\title{
laborhifórico
}

ISSN 2359-6910

https://revistas.ufrj.br/index.php/lh/

ARTIGO

Recebido em 26 de outubro de 2020

Aprovado em 05 de janeiro de 2021

\section{Adstrato cultural por comercialización. Acerca de un anglicismo del español de Chile divulgado en las tiendas}

\author{
Cultural adstratum by commercialisation. An Anglicism in Chilean Spanish \\ disseminated in the shops
}

DOI: https://doi.org/10.24206/lh.v7i1.39169

\section{Carsten Sinner}

É formado em Tradução (Espanhol, Português / Alemão) e Alemão como Língua Estrangeira pela Universidade Humboldt de Berlim, doutorado em Linguística hispânica pela Universidade de Potsdam, com estágios doutorais em Barcelona e Tucson, e habilitado para cátedra pela Universidade Humboldt de Berlim. Desde 2008 é catedrático no Departamento de Linguística Aplicada e Translatologia da Universidade de Leipzig, onde leciona para os cursos de graduação em Translação, os Programas de Pós-Graduação em Translatologia e Interpretação de conferências, e o Programa de Doutoramento da mesma Instituição.

E-mail: sinner@rz.uni-leipzig.de ORCID: https://orcid.org/0000-0002-5394-7041

\section{Constanza Gerding Salas}

Formada em Inglês como Língua Estrangeira pela Universidade Austral de Chile, doutorada em Educação pelas universidades de Estocolmo e Concepción, com estágios na Suécia, foi professora associada de Linguística comparada, Teoria da tradução e Inglês na Universidade de Los Lagos (Osorno) e na 
Universidade de Concepción onde fez parte do Grupo de Estudos Terminológicos e dirigiu um Grupo de Estudos da Neologia. Atualmente leciona no Programa do Magíster em Inovação do Ensino do Inglês. Desenvolve pesquisa nas áreas de terminologia, neologia, tradução e didática da tradução.

E-mail: cgerding@udec.cl ORCID: https://orcid.org/0000-0002-8248-3389 


\section{RESUMEN}

El presente trabajo aborda un aspecto original del influjo interlingüístico inglés-español, reflejado en una unidad léxica actualmente en uso en las diferentes variedades diasistemáticas del español de Chile: berry/berries. La contribución muestra la ruta recorrida por este anglicismo desde su ingreso hasta su asentamiento. Para ello, se estudió la unidad léxica/terminológica a través de la observación de sus manifestaciones en diversos contextos y tipologías textuales, y su uso fue refrendado por una variedad de informantes, de legos a especializados, a lo largo de una década. Se logró establecer la lógica que dio lugar a la trayectoria de su incorporación en la lengua desde su ingreso con fines netamente comerciales hasta su establecimiento y uso extendido en la variedad chilena, donde se ha asentado con un sentido hiperonímico que trasciende el de la lengua de origen. A partir de la reflexión, se puede explicar que este fenómeno de integración de préstamo es distinto a los procesos habituales de innovación por préstamo y, en consecuencia, se propone una subcategoría especial sobre la base del origen funcional del préstamo a la que hemos llamado adstrato cultural por comercialización.

Palabras clave: Anglicismo berry en el español de Chile. Adstrato cultural por comercialización. Mercadotecnia. Globalización. Nombres de productos.

\section{ABSTRACT}

This paper addresses an original aspect of English-Spanish interlinguistic influence, exemplified by a lexical unit currently in use in the diverse diasystematic varieties of Chilean Spanish: berry/berries. The contribution shows the path followed by this Anglicism since it was introduced into Chilean Spanish until it settled on the language. For this purpose, this lexical/terminological unit was examined through observation of its manifestations in various contexts and text types, and its use was confirmed along a decade by a variety of interviewees, from laymen to experts. It was possible to establish the logic underlying the trajectory of its incorporation into the language from its entry based upon purely commercial purposes to its establishment and widespread use in the Chilean variety of Spanish, where it has settled with a hyperonymic sense that transcends that of the source language. Upon reflection, it is possible to explain that this loan integration phenomenon differs from other regular innovation processes by loan; consequently, a special subcategory based on the functional origin of this loanword is proposed: cultural adstratum by commercialisation. 
Keywords: Anglicism berry in Chilean Spanish. Cultural adstratum by commercialisation. Marketing. Globalisation. Product names. 


\section{Introducción}

El contacto de lenguas es un tema central de la lingüística contemporánea y se tiene en cuenta en los más diversos ámbitos de la disciplina, como en la historiografía de la lengua y los estudios centrados en el análisis del cambio lingüístico, en la morfología, en la lexicología, en la terminología, en la sociolingüística, e incluso en los estudios lingüísticos en el seno de los estudios de la traducción e interpretación. Desde hace mucho tiempo, y debido al destacado papel del inglés como lengua de gran peso y presencia internacional evidente, los anglicismos son objeto de particular atención en un amplio abanico de subdisciplinas lingüísticas y desde diferentes perspectivas y vertientes teóricas.

La influencia del inglés sobre otras lenguas se ha relacionado muchas veces con el impacto de los medios de comunicación y, desde el auge de la comunicación mediada electrónicamente, como por diferentes dispositivos electrónicos (como ordenador, teléfono móvil, etc.) y diferentes aplicaciones (como WhatsApp), de una manera generalizadora con los diferentes medios aludidas generalmente como "nuevos medios" (cf. SINNER, 2016 ${ }^{1}, 2017^{2}$ ). Esta idea del impacto de los medios de comunicación cobra especial peso en el contexto de idiomas cuyos hablantes no están en contacto directo con el inglés, es decir, que no viven en una situación de bilingüismo societal, que no viven en zonas colindantes con territorios de habla inglesa o en países oficialmente bilingües o plurilingües (como Canadá o Singapur), o cuando en la sociedad en cuestión los contactos directos con hablantes del inglés se limitan al nivel individual, pero no constituyen un fenómeno social (como en países donde el inglés si bien no es lengua nativa de la población, sí es vehículo de la educación, lengua de la administración, etc., como, por ejemplo, en Malta).

Sin embargo, se ha podido mostrar que no solo en muchos casos de elementos cuyo uso se ha relacionado con películas dobladas, publicidad, etc., el impacto sobre el empleo en la lengua no es permanente, sino que, además, generalmente resulta prácticamente imposible probar empíricamente el papel de los medios en el uso lingüístico de la sociedad y establecer una relación causal inequívoca con el uso o adopción de ciertos elementos considerados como anglicismos (cf. SINNER, 2016², $\left.2017^{4}\right)$.

\footnotetext{
${ }^{1}$ SINNER, Carsten. Mito y realidad del impacto de los nuevos medios de comunicación en la lengua. El caso del castellano. In: CARRISCONDO ESQUIVEL, Francisco M. (Ed.). El español como noticia y el español de los medios. Vigo: Editorial Academia del Hispanismo, 2016, p. 161-207.

${ }^{2}$ SINNER, Carsten. Language Change through Medial Communication. In: BEDIJS, Kristina Bedijs / MAASS, Christiane (Ed.). Manual of Romance Languages in the Media. Berlin / Boston: de Gruyter Mouton, 2017, p. 381-410.

${ }^{3}$ SINNER, 2016, op. cit.

${ }^{4}$ SINNER, 2017, op. cit.
} 
El objetivo del presente trabajo es investigar un aspecto particular del contacto entre el inglés y el español de Chile y enfocar de forma ejemplar un elemento resultante de este contacto, a partir de una metodología que responde a un diseño mixto en el que, partiendo de introspección y observación, se incluyó, además del análisis de textos, también entrevistas, encuestas y estudio de campo (cf. SINNER; GERDING SALAS, 20205). La contribución se propone analizar el papel de la comercialización de productos en la incorporación en el español de Chile de una voz procedente del inglés, berry, berries (y variantes), empleada en forma creciente como equivalente de lexemas como bayas, frutas del bosque, frutos rojos, etc. usuales en otras variedades diatópicas, y trazar el papel de ciertas medidas de mercantilización en la ruta de la evolución de este anglicismo en el contexto chileno.

\section{Antecedentes}

El estudio que da lugar a este artículo tuvo su inicio con la observación de usos del aparente anglicismo berry/berries (y diferentes variantes ortográficas de estas formas) en el español escrito de Chile alrededor del año 2010, en diferentes contextos que resultaban sorprendentes a uno de los dos coautores, extranjero con otra lengua materna. Le llamó la atención por usarse en vez de otras formas que sí conocía de otras variedades del español, como, por ejemplo, bayas, frutas del bosque y frutos rojos, así como por aparecer en combinaciones con otros elementos léxicos que le resultaban inesperados, desde la perspectiva del hablante de una variedad europea del español. A la coautora chilena, sin embargo, la forma no le había llamado la atención más allá de la mera constatación de que se trataba de un anglicismo. Como consecuencia del asombro inicial, prestamos más atención a las situaciones en las que aparecía berry/berries y los significados o connotaciones que tenía (o podría tener).

Aquí cabe señalar que la observación (y con ella, la introspección) es uno de los motores más importantes de la investigación científica. No cabe duda de que al observar la lengua, la evaluamos, y esto conlleva, siempre, introspección. De hecho, junto con el experimento (y la posibilidad de repetirlo), la exactitud en la expresión, así como la precisión en la determinación y descripción del objeto de estudio y del proceso de la investigación, la observación llegó a formar, a lo largo de la historia de las ciencias, lo que se considera una aproximación científica a un asunto (cf. SINNER, $\left.2012^{6}\right)$.

\footnotetext{
${ }^{5}$ SINNER, Carsten; GERDING SALAS, Constanza. La introducción del anglicismo berry/berries en el español de Chile: historia, proceso integrativo y consecuencias semánticas. Zeitschrift für romanische Philologie, v. 136, n 3 , p. 789-832, 2020.

${ }^{6}$ SINNER, Carsten. Wissenschaftliches Schreiben in Portugal zum Ende des Antigo Regime (1779-1821). Die Memórias económicas der Academia das Ciências de Lisboa. Berlin: Frank\&Timme, 2012.
} 
Con la excepción de algunos enfoques lingüísticos, hoy se espera que en la investigación se vaya más allá de la mera introspección y del juicio individual de lo que se observa. Sin embargo, hay que tener siempre presente que quienes investigan la lengua también son hablantes con un idiolecto propio. La evaluación lingüística realizada por parte del lingüista depende esencialmente de su idiolecto, y los resultados de sus estudios obviamente también dependerán de esta variedad individual plasmada tanto en el empleo de la lengua como en la forma en la que el individuo la interpreta (OKSAAR, 1987 $; 2000^{8}$; SINNER, 2014 ${ }^{9}$ ). Esto constituye, obviamente, un aspecto importante en la manera en cómo se aborda una cuestión, y también es un factor determinante de la criba de material lingüístico y necesariamente constituye la base para la identificación de determinados aspectos por parte de los investigadores. ${ }^{10}$

Fue así que en 2010 comenzamos a realizar un estudio longitudinal enfocado en la observación del uso de berry/berries, en el que a una primera fase de observación y anotación de datos observados, en la que se constató que una extensión cada vez mayor y un posible cambio semántico de la forma, siguió el análisis pormenorizado de la adopción de berry/berries en el español de Chile. Se analizó, para ello, el trasfondo histórico y social en el que se inició la introducción de la voz en Chile, y se realizó una descripción lexicográfica contrastiva de berry y sus equivalentes en castellano. Se estudió el papel que desempeñan expertos, divulgadores y legos, representantes de tres ámbitos de variación diastrática, en la incorporación de esta voz en el español de Chile, examinándose pormenorizadamente la relación entre las denominaciones existentes. Se analizaron los indicios neológicos -género gramatical, ortografía y marcas tipográficas- y se realizó una descripción morfológica clasificatoria de las diferentes posibilidades combinatorias de berry/berries y otros elementos documentadas. Para ello, se analizó la aparición de berry/berries con variantes ortotipográficas y alternativas léxicas en la revista Campo, de Chile, de 1985, 1996, 2012 y en las ediciones de junio de 2016 a marzo de 2019, así como en los números desde abril de 2016 a abril de 2019 de la revista divulgativa del sector agropecuario, forestal y agroindustrial Campo Sureño; entre 2010 y 2018, se realizaron entrevistas con respecto al anglicismo en cuestión a 300 estudiantes de Traducción de las universidades chilenas de Concepción y Católica de Temuco así como con una veintena de lingüistas, periodistas, traductores profesionales y

OKSAAR, Els. Idiolekt. In: AMMON, Ulrich; DITTMAR, Norbert; MATTHEIER, Klaus J. (Eds.). Sociolinguistics. Soziolinguistik. An International Handbook of the Science of Language and Society. Ein Internationales Handbuch zur Wissenschaft von Sprache und Gesellschaft. 2 vols. Berlin: de Gruyter, Vol 1, 293-297, 1987.

${ }^{8}$ OKSAAR, Els. Idiolekt als Grundlage der variationsorientierten Linguistik. Sociolinguistica 14, 37-42, 2000.

${ }^{9}$ SINNER, Carsten. Varietätenlinguistik. Eine Einführung. Tübingen: Narr, 2014.

${ }^{10}$ Puede ser diferente en el caso de que se emplee un sistema de categorización independiente de la opinión e intuición de los investigadores y no propicio para ser influido por ellos, como son, por ejemplo, sistemas automáticos de análisis de textos y extracción, búsqueda automática de corpus, etc. No obstante, en sentido estricto, también en este caso juega un papel el idiolecto, ya que puede determinar, por ejemplo, el etiquetado de corpus, influir en la selección de material lexicográfico que sirve de base para hacer contrastes, etc. 
expertos en producción y comercialización agropecuaria chilenos; entre 2010 y 2018, se hizo un seguimiento longitudinal de la aparición de las formas en cuestión en rótulos de venta, menús y etiquetas de productos en diversas tiendas, supermercados, cafeterías y restaurantes chilenos de la Región del Bío Bío, la Región de Los Ríos y la Región de la Araucanía; en abril, mayo y junio de 2019 se hizo un levantamiento de la rotulación de productos envasados en una sucursal de una de las cadenas de supermercados con mayor variedad de productos en Chile y presencia en gran parte del territorio nacional; se realizaron vaciados de diversos corpus del español ${ }^{11}$; y en 2019 y 2020, se realizaron análisis semánticos, morfológicos, neológicos y estadísticos de los materiales recogidos.

\section{Historia y evolución del anglicismo en el contexto chileno}

Pudo determinarse que el empleo de la palabra berry en Chile se impulsa, a principio de los años 80 del siglo XX, con una propuesta realizada por la Fundación Chile a Augusto Grob Fuchs (un empresario chileno ligado a agricultura, la ganadería y la agroindustria de La Unión, actual Región de Los Ríos, Chile), en el sentido de cultivar diversos frutos del tipo baya y similares en el sur de Chile.

La Fundación Chile, conformada por el Gobierno de Chile y BHP Billiton-Minera Escondida una empresa de recursos naturales cuyo propósito es crear valor para accionistas en el largo plazo a través del descubrimiento, adquisición, desarrollo y comercialización de recursos naturales (BHP BILLITON, 2019 ${ }^{12}$ ) es una corporación de derecho privado, sin fines de lucro, creada en 1976 (FUNDACIÓN CHILE, 2019, s.p. ${ }^{13}$ ) con el objetivo de fomentar, en Chile, la innovación y el emprendimiento en las áreas de sustentabilidad, alimentos y acuicultura, capital humano, educación y emprendimiento.

Como señala la propia Fundación Chile (2015, s.p. $\left.{ }^{14}\right)$, en 1980 ya realizó "las primeras pruebas de procesos y comercialización de frambuesas, moras y frutillas, más conocidas como berries”. En 1985, la idea se materializa con la creación de la compañía Berries La Unión S.A., como consecuencia de la asociación de Grob Fuchs con otros agricultores de la zona; juntos establecen huertos frutales,

REAL ACADEMIA ESPAÑOLA. Corpus Diacrónico del Español (CORDE). Disponible en: http://corpus.rae.es/cordenet.html; REAL ACADEMIA ESPAÑOLA. Corpus de Referencia del Español Actual (CREA). Disponible en: http://corpus.rae.es/creanet.html; DAVIES, Mark. Corpus del español. Disponible en: https://www.corpusdelespanol.org/hist-gen/.

${ }^{12}$ BHP BILLITON. BHP. 2019. Disponible en https://www.bhp.com/espanol. Acceso: 02.08.2019.

${ }^{13}$ FUNDACIÓN CHILE. Berries. 2015. Disponible en https://fch.cl/berries-2/. Acceso: 12.07.2019.

${ }^{14}$ FUNDACIÓN CHILE, 2015, op. cit. 
principalmente destinados al cultivo de arándanos (CHRISTIAN $1988^{15}$ ) con fines comerciales a gran escala. La voz arándano se emplea en castellano para distintos referentes, principalmente el arándano azul o americano, Vaccinium corymbosum, y el arándano (europeo) o mirtilo, Vaccinium myrtillus; en Chile suele usarse para denominar diferentes variedades, también las provenientes de cruces de Vaccinium corymbosum con Vaccinium darrowii (cf. REDAGRÍCOLA 2019 ${ }^{16}$ ). Se sabe que en la historia de las lenguas es un procedimiento frecuente emplear nombres de realidades existentes para referirse a "nuevas" realidades que se les parecen, a veces especificando con un adjetivo calificativo adicional. Fue así como buena parte de la flora y fauna americana recibió sus denominaciones en español, portugués, francés e inglés, ante todo, como muestran nombres como Porco tacajú para el pecarí de la familia de los Tayassuidae en portugués (WOLL, 2011 ${ }^{17}$; SINNER, 2012, 507-520 $0^{18}$.

A partir de 1986, a través del Programa de Desarrollo de Nuevas Especies, se introducen nuevas variedades en Chile, como cranberry (Vaccinium macrocarpon), sanddorn (Hippophae rhamnoides) y lingonberry (Vaccinium vitis-idaea) ${ }^{19}$ (cf. FUNDACIÓN CHILE 2015 ${ }^{20}$ ). En este contexto, cabe señalar que además del nombre cranberry, en el español de Chile existe también la denominación arándano rojo grande, lo que habrá contribuido a la confusión de las diferentes especies comercializadas como berries, tanto más cuando arándano y arándano rojo, a su vez, pueden referirse a diferentes especies: Vaccinium oxycoccus (también llamado en español arándano rojo común, arándano rojo del norte), Vaccinium macrocarpos (para el arándano americano) Vaccinium microcarpon (llamado, también, en español, arándano rojo pequeño) y, finalmente, el Vaccinium erythrocarpum (también llamado arándano rojo de las montañas del sur). El germanismo sanddorn aquí se empleó en vez de una las formas usuales en castellano: espino amarillo, escambrón, cambrón, espino falso, arto, quitasombreros y titinera (cf. INTERNATIONAL UNION FOR THE PROTECTION OF NEW VARIETIES OF PLANTS $\left.2008^{21}\right)$.

\footnotetext{
${ }^{15}$ CHRISTIAN, Shirley. After Turmoil, Foundation Finds Profit. In: South Florida SunSentinel, 12.09.1988, www.sun-sentinel.com/news/fl-xpm-1988-09-12-8802220574-story.html. Acceso: 09.08.2019.

${ }^{16}$ REDAGRÍCOLA. Arándanos. Entrevista al asesor internacional Sebastián Ochoa. Variedades de arándano para una industria ya madura. Redagrícola. Junio 2019. Disponible en www.redagricola.com/cl/variedades-dearandano-para-una-industria-ya-madura/\#: :text=En\%20la\%20zona\%20norte\%20de\%20Chile\%20queremos\%20varie dades\%20que\%20se,de\%20gran\%20desarrollo\%20en\%20Perú. Acceso: 25.10.2020.

${ }^{17}$ WOLL, Dieter. Der ,Mais‘ wird zur ,Hirse', der, Jaguar zum ,Tiger': europäisch-portugiesische Wörter für Dinge der Neuen Welt. In: ENDRUSCHAT, Annette / SCHÖNBERGER, Axel (Eds.). Neue Beiträge zur portugiesischen Sprachwissenschaft. Frankfurt am Main, TFM, 11-47, 1999.

${ }^{18}$ SINNER, 2012, op. cit.

${ }^{19}$ El nombre inglés lingonberry compite con otras denominaciones como cowberry, mountain cranberry y partridgeberry. Las últimas dos, a su vez, son también nombres comunes de otras variedades de bayas.

${ }^{20}$ FUNDACIÓN CHILE, 2015, op. cit.

${ }^{21}$ INTERNATIONAL UNION FOR THE PROTECTION OF NEW VARIETIES OF PLANTS / Internationaler Verband zum Schutz von Pflanzenzüchtungen. Sanddorn. UPOV-Code HIPPH_RHA. Hippophae rhamnoides L. Richtlinien für die Durchführung auf Unterscheidbarkeit, Homogenität und Beständigkeit. Genf: UPOV, 2008.
} 
Para aumentar el rendimiento agrícola y mejorar la calidad y, así, la comerciabilidad de los productos, se introdujeron en Chile variedades híbridas de arándanos azules: las variedades O’Neal, Georgia Gem y Misty, exentas de derechos de propiedad, por lo que pueden ser cultivadas libremente, además tienen "bajo requerimiento de frío, maduran más temprano, producen fruta de mejor calidad y arbustos más pequeños y más fáciles de manejar" (INSTITUTO DE INVESTIGACIONES AGROPECUARIAS, 2013, $18^{22}$ ).

Una vez establecidas las plantaciones comerciales de estos frutos en Chile, en 1987 se dio inicio a las primeras exportaciones de berries (GONZÁLEZ FERNÁNDEZ, 2007²3), y como resultado del gran éxito de las ventas al extranjero, principalmente de arándanos, se establecieron también plantaciones comerciales de frambuesas (Rubus idaeus), grosellas (Ribes uva-crispa, también llamada Ribes grossularia), frutillas (distintas variedades de Fragaria $x$ ananassa) ${ }^{24}$ y zarzaparrillas rojas y negras (Ribes rubrum y Ribes nigrum), en diversos predios de la que hoy es la Provincia del Ranco. Gracias a sus condiciones agroclimáticas, en la Región del Bío Bío (situada a unos $500 \mathrm{~km}$ al norte de las primeras plantaciones de berries) se inicia también el cultivo masivo de diversos frutales de exportación, "entre los que sobresalen los berries (arándanos, frambuesas y frutillas) y cuyo cultivo representa el 22\% de la superficie nacional" (INSTITUTO DE INVESTIGACIONES AGROPECUARIAS, 2013, $5^{25}$ ).

En el plano técnico, la voz berry aparece usada por primera vez -en plural-, en registros oficiales chilenos en la Resolución N².954 Exenta, del Ministerio de Agricultura, publicada en el Diario Oficial el 3 de octubre de 1996, en un decreto que establece normas para el funcionamiento de viveros y depósitos de plantas (BIBLIOTECA DEL CONGRESO NACIONAL DE CHILE, 2019²6).

Después, berry/berries comienza a cobrar importancia y visibilidad en textos de semidivulgación, como, por ejemplo, los artículos sobre temas agrícolas publicados en la revista semanal Campo (DYCK, 2018 ${ }^{27}$ ) cuyo objetivo es informar sobre la actualidad agropecuaria chilena e internacional y dar orientación a los agricultores para mejorar la producción y la productividad de la agroindustria.

\footnotetext{
${ }^{22}$ INSTITUTO DE INVESTIGACIONES A GROPECUARIAS (INIA). Manual de Arándano. 2013. Disponible en http://biblioteca.inia.cl/medios/biblioteca/boletines/NR39094.pdf. Acceso: 24.08.2019.

${ }^{23}$ GONZÁleZ FERNÁNDEZ, Rodrigo. Los Grob en La Unión. AGRICULTURA BLOGGER. Defendamos nuestra Agricultura una forma de vida. 2007. Disponible en: http://agriculturablogger.blogspot.com/2007/10/losgrob-en-la-union-e-la-revista-del.\%20html. Acceso: 14.07.2019.

${ }^{24}$ En este trabajo usamos las denominaciones comunes en Chile; frutilla, por ejemplo, es el equivalente de lo que en otras variedades se llama fresa o fresón.

${ }^{25}$ INSTITUTO DE INVESTIGACIONES AGROPECUARIAS, 2013, op. cit.

${ }^{26}$ BIBLIOTECA DEL CONGRESO NACIONAL. Modifica resolución No. 1.910 de 1982 sobre normas para criaderos, viveros y depósitos y deroga resolución No. 760 de 1989. 2019, Disponible en: www.leychile.cl/Navegar?idNorma=245622\&idParte=\&idVersion=2011-02-17, versión corta de la URL https://bcn.cl/27nt4. Acceso: 19.07.2019.

${ }^{27}$ DYCK, Gabriela. Zur Entwicklung des Terminus berries im chilenischen Spanisch zwischen 1985 und 2012. Tesis de máster. Leipzig: Institut für Angewandte Linguistik und Translatologie, Universität Leipzig, 2018.
} 
Con el éxito de estas producciones agrícolas, también se inició o aumentó la producción y comercialización de otros frutos ahora vendidos como berries, como la murta (Ugni molinae) (que en Chile recibe una larga serie de nombres locales diferentes, entre ellos, murta blanca, murtilla, mutilla, murtina, tautau así como uñi), la mora (Rubus sect. Rubus) (también llamada murra en el sur del país, lo que se ha explicado con el impacto de la emigración germanohablante a esta zona), el maqui (Aristotelia chilensis) y los diferentes tipos de baya del género Berberis nativas de Argentina y Chile conocidas como calafate y michay (Berberis microphylla, Berberis congestiflora, Berberis darwinii y otros), y Chile hoy es uno de los países que más berries producen para la exportación (THIS IS CHILE. PORTAL OFICIAL DE CHILE 2010², CASTRO 2018, $4^{29}$ ). En la última década, Chile llegó a exportar alrededor de 50 especies de frutas y hortalizas y las especies frutícolas con mayor dinamismo e impacto en la economía regional son las que se subsumen bajo el denominador berries, tanto cultivados como silvestres (REGIÓN DE LOS RÍOS, GOBIERNO REGIONAL, $2016^{30}$ ).

Debido a la mayor disponibilidad de estas bayas en el mercado nacional, como resultado del descarte de exportación que queda para consumo interno, así como la mayor conciencia que ha ido adquiriendo la sociedad chilena con respecto al aporte nutricional de estos frutos y los consiguientes beneficios de su consumo para la salud, los chilenos se han ido convirtiendo en buenos consumidores de berries. Así, el vocablo, antes limitado a discursos especializados y semiespecializados, ingresa y permanece en otros ámbitos de la lengua española en Chile.

La aceptación lexicográfica de la palabra berry en el español de Chile se produce en 2010, con la publicación del Diccionario de uso del español de Chile; esta obra lexicográfica descriptiva de la Academia Chilena de la Lengua incorpora unidades léxicas vigentes en la variedad chilena actual del español que "tienen carácter diferencial, es decir, que no pertenecen al español general" (INSTITUTO DE CHILE, 2019³1). Además, en el mismo año, berry se incluyó también en el Nuevo Diccionario Ejemplificado de Chilenismos (MORALES PETTORINO, 2010 32). Sin embargo, la voz sigue sin incluirse en la mayor parte de las obras lexicográficas del castellano como, por ejemplo, el Diccionario de la Lengua Española de la REAL ACADEMIA ESPAÑOLA / ASOCIACIÓN

\footnotetext{
${ }^{28}$ THIS IS CHILE. PORTAL OFICIAL DE CHILE. El boom de los berries chilenos. 22.01.2010, Disponible en https://www.thisischile.cl/el-boom-de-los-berries-chilenos/. Acceso: 04.09.2019.

${ }^{29}$ CASTRO, Lorena. A disfrutar de los berries este verano. Siminforma 491 (diciembre de 2018). Disponible en: http://www.siminforma.com.mx/Siminforma-Chile/pdf/491.pdf. Acceso: 19.07.2019.

${ }^{30}$ REGIÓN DE LOS RÍOS, GOBIERNO REGIONAL. Los Ríos. Región de oportunidades. Propuestas de Inversión, Corporación Regional de Desarrollo Productivo. 2016. Disponible en: https://corporacionlosrios.cl/index.php/files/419/Propuestas\%20de\%20Inversion/754/Descargar\%20aqui.pdf. Acceso: 27.08.2019.

31 INSTITUTO DE CHILE. Diccionario de uso del español de Chile. 2019. Disponible en www.institutodechile.cl/lengua2/diccionario-de-uso-del-espanol-de-chile/. Acceso:19.07.2019.

32 MORALES PETTORINO, Félix. Nuevo diccionario ejemplificado de chilenismos, edición refundida y actualizada. Valparaíso: Puntángeles, 2010.
} 
DE ACADEMIAS DE LA LENGUA ESPAÑOLA (201933), el Diccionario general de la lengua española $\left(2011^{34}\right)$, que es la nueva versión del Diccionario de uso del español de América y España, o en el Diccionario de uso del español (MOLINER 2008 ${ }^{35}$ ).

\section{Formas y significados}

Para completar la mirada sobre la perspectiva lexicográfica, cabe considerar las perspectivas de los diccionarios del inglés sobre la voz berry y de los diccionarios españoles sobre baya. Resulta que se constata bastante contradicción y confusión entre los niveles técnico y general. Para LEXICO, desarrollado por Dictionary.com y la Oxford University Press, la voz berry presenta dos siguientes acepciones, en lo que respecta a fruta:

(1) A small roundish juicy fruit without a stone. "Whether you are fortunate enough to have a garden bursting with ripening soft fruits, berries and currants, or whether you buy them at the shops, this is the time to indulge.'

(2) Botany. Any fruit that has its seeds enclosed in a fleshy pulp, for example a banana or tomato. 'Drupes and berries, the classic fleshy fruits, first appeared in the late Cretaceous or early Tertiary.' (LEXICO, sin fecha, s.v. ${ }^{36}$ )

Para el Cambridge Dictionary (CAMBRIDGE UNIVERSITY PRESS, sin fecha ${ }^{37}$ ), por citar otra obra lexicográfica británica de prestigio, la voz no plantea ninguna complejidad; sencillamente define berry como "a small, round fruit on some plants and trees" (s.v.), con el equivalente español baya. Al consultar el Merriam-Webster $\left(\sin \mathrm{fecha}^{38}\right)$, un diccionario monolingüe de procedencia estadounidense, en cuanto a frutas, se observa que berry también tiene dos acepciones, pero estas solo coinciden en parte con las registradas en otras obras:

33 REAL ACADEMIA ESPAÑOLA / ASOCIACIÓN DE ACADEMIAS DE LA LENGUA ESPAÑOLA. Diccionario de la lengua española. Versión electrónica 23.3, actualización 2019. 2019. Disponible en: https://www.rae.es. Acceso: 19.10.2020.

${ }^{34}$ INDURÁIN PONS, Jordi (Ed.). Diccionario general de la lengua española. El vocabulario general del español de América y Europa. Tercera edición. Barcelona: VOX, 2011.

${ }^{35}$ MOLINER, María. Diccionario de uso del español. Gredos: Madrid, 2008.

${ }^{36}$ LEXICO. Oxford English and Spanish Dictionary, Thesaurus, and Spanish to English Translator. Sin fecha. Disponible en: www.lexico.com/en/english. Acceso: 07.07.2019.

${ }^{37}$ CAMBRIDGE UNIVERSITY PRESS. Cambridge Dictionary. Sin fecha. Cambridge: Cambridge University Press. Disponible en: https://dictionary.cambridge.org/es/. Acceso: 07.07.2019.

${ }^{38}$ MERRIAM-WEBSTER. Merriam-Webster. Sin fecha. Disponible en: https://www.merriam-webster.com. Acceso: 19.10.2020. 
(1) a pulpy and usually edible fruit (such as a strawberry, raspberry, or checkerberry) of small size irrespective of its structure

(2) a simple fruit (such as a grape, blueberry, tomato, or cucumber) with a pulpy or fleshy pericarp

Si comparamos las definiciones en inglés, observamos que los rasgos que comparten dentro de un mismo campo semántico son pocos (fruit, small, pulpy, fleshy), y que de los ejemplos aportados, se puede inferir que el término no se refiere a drupas, es decir, frutos de mesocarpio carnoso y endocarpio leñoso y de una sola semilla, como la cereza o la ciruela, sino a lo que, en el lenguaje botánico español, se llama baya, como el tomate y la uva, y otras frutas que si bien suelen llamarse así, botánicamente no se consideran bayas, como es el caso de la frambuesa y de la frutilla.

Veamos los diccionarios de español. El Diccionario de la Lengua Española (2019, s.v. ${ }^{39}$ ) incluye baya, definido como un "tipo de fruto carnoso con semillas rodeadas de pulpa; p. ej., el tomate y la uva”, y en el Diccionario general de la lengua española $\left(2011\right.$, s.v..$\left.^{40}\right)$ esta voz se registra como "fruto carnoso o pulposo con varias semillas en su interior que están envueltas directamente en la pulpa; suele tener forma redondeada o elipsoidal: las grosellas, las moras, los arándanos y las fresas son bayas". Se constata una clara discrepancia entre definición y ejemplos, porque las moras, a diferencia de las demás frutas mencionadas, están formadas por glóbulos, y las frutillas no tienen las semillas (botánicamente: aquenios) en su interior. También la definición de baya en el Diccionario de uso del español (Moliner 2008, s.v.) está acerca de la definición de lo que es berry en inglés en el lenguaje botánico y no en la lengua común: "fruto con el epicarpo delgado y el mesocarpo y endocarpo carnosos y más o menos jugosos, como el tomate”.

Como señala LORGE $\left(2013^{41}\right)$, las frutas, en general, no son fáciles de clasificar, por lo que no debe sorprender que no haya consenso, ni entre los divulgadores de la industria y de la prensa ni entre los consumidores, respecto del uso de berry en inglés y baya en español. De hecho, los usos pueden distar bastante de las definiciones botánicas (tampoco siempre unívocas) de estos frutos en ambas lenguas. Desde la perspectiva científica, en ambas lenguas ocurre lo mismo: hay frutas como los arándanos que común y biológicamente son berries o bayas; las que, como el plátano, la uva o el tomate, biológicamente lo son, pero que comúnmente no conocemos como tales, y las que, como las moras, las frambuesas y las frutillas, comúnmente clasificaríamos así sin que biológicamente lo sean. En SINNER; GERDING SALAS (2020) presentamos los resultados de un análisis de contextos

\footnotetext{
${ }^{39}$ REAL ACADEMIA ESPAÑOLA / ASOCIACIÓN DE ACADEMIAS DE LA LENGUA ESPAÑOLA, 2019, op. cit.

${ }^{40}$ INDURÁIN PONS, 2011, op. cit.

41 LORGE, Greta. Bananas are berries? Stanford Magazine July/August 2013. Disponible en: https://stanfordmag.org/contents/bananas-are-berries. Acceso: 05.07.2019.
} 
científicos, semidivulgativos o de prensa especializada en los que aparecen los términos aquí tratados, poniendo de relieve el desconcierto terminológico existente (cf. SINNER; GERDING SALAS 2020, 798-79942): ni en el español común ni en el lenguaje de los especialistas en botánica o en otras disciplinas se hace una diferenciación que se corresponda con las definiciones científicas de baya en español o de berry en inglés. Se constató que existen, por así decirlo, varias capas de definiciones y de usos, que interfieren entre sí, lo que lleva a un círculo vicioso, dado que los diccionarios reflejan parcialmente la norma y el uso, pero no relacionan de forma transparente los usos constatados con la perspectiva académica botánica.

Si bien en el caso de Chile, berries prácticamente no alterna con baya, sí se dan las confusiones o no diferenciaciones de los demás nombres genéricos, y se constata que, en la difusión científica en Chile, tampoco se hace una diferenciación tan clara como sería de esperar de expertos. Al evaluar los usos de berry en el español de Chile, cabe tener en cuenta que es un hecho conocido en los estudios morfológicos que, en la introducción de préstamos, las voces suelen o bien tomarse solo con una o algunas de sus acepciones originales o bien resemantizarse completamente (es decir: se adopta la forma, pero no el significado). Las resemantizaciones pueden ser ampliaciones o restricciones del significado original o incluso puede tratarse de cambios de significado por analogía, metáfora o metonimia (cf. GÓMEZ CAPUZ, 2009³; SANTAMARÍA, 2014 ${ }^{44}$ ). Esto hace imperativo obviar la semántica del étimo inglés al trabajar con textos en español, y determinar los significados de berry en español de Chile a partir de los usos.

Desde una perspectiva no botánica, pero sí semiespecializada, el empleo de berry en el español de Chile engloba un conjunto de frutos que, independientemente de su gestación, se caracterizan por ser pequeños, comestibles, pulposos y por tener, por lo general, semillas muy pequeñas. En diferentes contextos, berries se presenta explícitamente como sinónimo de bayas. Así, por dar un ejemplo del ámbito del comercio exterior, en INNOVACION.CL $\left(2015^{45}\right)$, un medio de comunicación digital destinado a impulsar la innovación y el emprendimiento en el país, se afirma que Chile "es el principal exportador de berries del hemisferio sur en volumen y valor, y el quinto exportador a nivel mundial. Sin embargo, los berries o bayas más exportados desde nuestro país son las frambuesas y arándanos". Las frutas que se mencionan en los textos como berries no siempre lo son, como ilustra la indicación de

\footnotetext{
${ }^{42}$ SINNER; GERDING SALAS, 2020, op. cit.

${ }^{43}$ GÓMEZ CAPUZ, Juan. El tratamiento del préstamo lingüístico y el calco en los libros de texto de bachillerato y en las obras divulgativas. Tonos digital: Revista electrónica de estudios filológicos 17, 2009. Disponible en: www.um.es/tonosdigital/znum17/secciones/tritonos-1-librosdetexto.htm. Acceso: 20.10.2020.

${ }^{44}$ SANTAMARÍA, Isabel. La representación de la resemantización en los diccionarios del español. Revista de Lexicografía 19, 139-166, 2013.

${ }^{45}$ INNOVACION.CL. El maqui, la murta y el calafate son propios de nuestro país. Berries nativos: Una nueva oportunidad para la exportación de Chile. Innovacion.cl. 25.02.2015. Disponible en: www.innovacion.cl/2015/02/berries-nativos-una-nueva-oportunidad-para-la-exportacion-de-chile/. Acceso: 20.10.2020.
} 
frutilla, frambuesa, arándano y mora en un elenco de berries mencionados en el Diagnóstico nacional del sector berries y taller de planificación estratégica del sector realizado por el Ministerio de Agricultura junto con ProChile, un organismo dependiente del Ministerio de Relaciones Exteriores encargado de promover las exportaciones, finalizado en 2001, y referido por GAMEZ BASTÉN $\left(2002^{46}\right)$.

Se ve que berry/berries se emplea con toda naturalidad en contextos en los que en otras variedades hispanas nunca aparece, si bien a veces se marca con cursiva o comillas, lo que lo identifica, potencialmente, como extranjerismo; además, se constata que la voz a menudo se equipara con bayas, lo que obliga a preguntarse por la razón del uso del anglicismo. Y se pudo determinar que en el español chileno berry "compite", por decirlo así, con una serie de lexemas usados como nombres genéricos, siendo los más frecuentes frutos rojos o frutas rojas, frutos del bosque o frutas del bosque, frutos silvestres o frutas silvestres, frutos menores o frutas menores y, finalmente, bayas (SINNER; GERDING SALAS 2020, 802 $2^{47}$ ). Además, la forma bayalbayas muy claramente solo aparece en el discurso científico o semiespecializado, y muy pocas veces se emplea por sí sola: casi siempre aparece acompañando a berry/berries, potencialmente para precisar esta forma.

Se constatan vacilaciones en la grafía y en la formación del plural -con soluciones como berrie o berrys- y en la asignación del género. Esta inestabilidad sistemática formal, propia de los neologismos en los que la innovación se da a través del préstamo, se debe a que el uso no está completamente fijado, porque su (probable) asentamiento en la lengua receptora está aún en proceso. En un análisis de las apariciones de berry/berries y sus alternativas ortográficas en la ya mencionada revista chilena Campo, se vio que de cero usos en los 47 números publicados en 1985, pasó a 42 apariciones en los 51 números del 1996 y a 93 ocurrencias en los 51 números publicados en 2012; y que en el año 2012, se produjo un aumento considerable, respecto de los resultados de 1996, del uso de las formas no marcadas, lo que sugiere que el vocablo se ha ido imponiendo en el español de Chile, también respecto de otras denominaciones, como frutos rojos (cf. DYCK 2018, 39, 41 ${ }^{48}$ ). ${ }^{49} \mathrm{Y}$ pudimos demostrar, empleando el mismo corpus de la revista Campo, que berry inicialmente presenta mucha

\footnotetext{
${ }^{46}$ GAMEZ BASTÉN, María Eugenia. El sector berries en Chile. [Página web de la] Oficina de Estudios y Políticas Agrarias del Gobierno de Chile, 12.03.2002. Disponible en: www.odepa.gob.cl/publicaciones/articulos/el-sectorberries-en-chile-2002. Acceso: 20.10.2020.

${ }^{47}$ SINNER; GERDING SALAS, 2020, op. cit.

${ }^{48}$ DYCK, 2012, op. cit.

${ }^{49}$ En las variedades diatópicas del castellano tenemos diferentes preferencias por la forma frutas y frutos con el mismo significado. Dejando de lado aquí el uso de fruto y fruta como nombres colectivos, se ve que en el español de Chile casi exclusivamente se encuentra el uso en masculino; cf. los resultados del estudio de LEGUE GONZÁLEZ, Ana; SANDOVAL HERNÁNDEZ, Catalina. ¿Helado de berries o de frutos del bosque? Variantes ortotipográficas y frecuencia de uso del anglicismo berry y de sus equivalentes en español. Tesis para optar al grado de Licenciado. Concepción: Universidad de Concepción, 2019, 40, realizado en el marco del proyecto, en el que se aborda la frecuencia de uso y las variantes ortotipográficas de berry y sus equivalentes en español en prensa semiespecializada y en productos frescos y manufacturados que se comercializan en Chile, y en el que se determinó que la forma frutas rojas solo apareció en un $2 \%$ de los productos analizados: en etiquetas de dos vinos chilenos que también se exportan.
} 
variación de género, pero que la forma masculina prevalece y la forma femenina disminuye en frecuencia a lo largo de los años (SINNER; GERDING SALAS, 2020 $0^{\circ 0}$ ), lo que va acorde con otros estudios que dan cuenta del amplio uso del masculino como género "por defecto" para los préstamos en el español de Chile (cf. GERDING SALAS; FUENTES MORRISON; KOTZ GRABOLE, $2012^{51}$ ). Junto con las marcas tipográficas ya mencionadas, las diversas manifestaciones de inestabilidad son un claro indicio neológico, es decir, señal de un proceso no concluido de naturalización del lexema que se ha tomado prestado (si bien el grado de adaptación a las normas morfológicas, fonéticas y ortotipográficas no tiene que correlacionarse con la integración social de un elemento).

En un estudio longitudinal realizado entre 2010 y 2018, pudimos demostrar, mediante consultas a más de 300 estudiantes chilenos hablantes maternos de español, de ambos sexos, de diferentes grupos etarios y distintos niveles sociales, que el préstamo berry ha ido instalándose de forma espontánea o insidiosa en el inventario léxico de los chilenos. De hecho, los informantes no parecían objetar su uso ni incomodarse por la presencia del anglicismo en la prensa o en las etiquetas de productos de consumo cotidiano (cf. SINNER; GERDING SALAS, 202052). En este contexto, queremos hacer hincapié en el hecho de que los préstamos constituyen un 30\%, aproximadamente, de las innovaciones léxicas en el castellano de Chile, y que el $80 \%$ de ellos se toman del inglés (GERDING SALAS; FUENTES MORRISON; KOTZ GRABOLE, 2012 ${ }^{53}$ ), por lo era esperable que la incorporación del anglicismo aquí analizado no produjera asombro a los hablantes encuestados. De hecho, nadie protestó contra el uso del vocablo en sí, y las únicas objeciones que hubo las formulaban informantes que pueden considerarse profesionales de lengua inglesa -traductores, profesores de lengua) - y que criticaban aspectos formales, como un singular berrie, un plural berrys o grafías con una sola $<\mathrm{r}>$.

\section{Debate}

Los préstamos del inglés -y entre ellos, berry/berries- tienen actualmente una importancia significativa para la innovación léxica de distintas variedades del español (NOVOTNÁ 2007 ${ }^{54}$;

\footnotetext{
${ }^{50}$ SINNER; GERDING SALAS, 2020, op. cit.

${ }^{51}$ GERDING SALAS, Constanza; FUENTES MORRISON, Mary; KOTZ GRABOLE, Gabriela. Anglicismos y aculturación en la sociedad chilena. Onomázein 25, 139-162, 2012.

${ }^{52}$ SINNER; GERDING SALAS, 2020, op. cit.

${ }^{53}$ GERDING SALAS; FUENTES MORRISON, KOTZ GRABOLE, 2012, op. cit.

${ }^{54}$ NOVOTNÁ, Markéta. El anglicismo en la lengua española. Brno: Masarykova univerzita, 2007. Disponible en: https://is.muni.cz/th/145734/ff_b/bakalarska_diplomova_prace.pdf. Acceso: 02.10.2020.
} 
GERDING SALAS; CAÑETE GONZÁLEZ; ADAM, 2018 ${ }^{55}$ ) y tienen mayor o menor gravitación en las distintas variedades, en dependencia de factores sociales, culturales, políticos, etc. Como consecuencia, el préstamo del inglés como forma de innovación léxica se presenta, de manera más o menos intensa, en distintos ámbitos temáticos y variedades diasistemáticas, y obedece, en gran medida, al vertiginoso avance de la ciencia y la tecnología, a la participación de muchos países en la economía global y a la influencia lingüístico-cultural estadounidense en muchas sociedades actuales (GERDING SALAS; CAÑETE GONZÁLEZ; ADAM, 201856). Al mismo tiempo, la adopción y la adaptación de préstamos obedecen no solamente a la necesidad de llenar vacíos denominativos, sino que, a veces, en este proceso intervienen otros factores, como, por ejemplo, el estilístico (GERDING SALAS et al., $\left.2019^{57}\right)$.

A lo largo del proyecto, se observó la aparición de berry/berries en más y más contextos, y sobre la base de los resultados de los análisis de la documentación escrita recogida, las entrevistas y los análisis estadísticos, se llegó a la conclusión del siguiente orden de expansión:

- Inicialmente, se emplea como parte del nombre de empresas agroindustriales (como Berries La Unión S.A., 1985), idea que se ha aplicado con el tiempo a otras empresas de distintos lugares del país (por ejemplo, Empresas Berries Sur, de Valdivia; Best Berry S.A., de Los Ángeles; Berries Fruits Chile, de Curicó).

- Luego, se observa su uso en textos especializados y semiespecializados ("loganberry, blaclcberry [sic], boysenberry", MINISTERIO DE AGRICULTURA DE CHILE, 1989 ${ }^{58}$ ).

- Paulatinamente, empieza a aparecer en la prensa local y nacional (al inicio, en textos sobre las actividades agroindustriales, como, por ejemplo, artículos sobre el establecimiento de plantaciones de berries o, más tarde, "[e]1 boom de los berries chilenos", THIS IS CHILE. PORTAL OFICIAL DE CHILE, 20105).

\footnotetext{
${ }^{55}$ GERDING SALAS, Constanza; CAÑETE GONZÁLEZ, Paola; ADAM, Carolin. Neología sintagmática anglicada en español: Calcos y préstamos. Revista Signos. Estudios de Lingüística 51, 175-192, 2018. DOI: http://dx.doi.org/10.4067/S0718-09342018000200175.

${ }^{56}$ GERDING SALAS; CAÑETE GONZÁLEZ; ADAM, 2018, op. cit.

${ }^{57}$ GERDING SALAS, Constanza, et al. Los periodistas y su responsabilidad en la incorporación de préstamos en español. Boletín de Filología 54, 1, 231-254, 2019. DOI: http://dx.doi.org/10.4067/S0718-93032019000100231.

${ }^{58}$ MINISTERIO DE AGRICULTURA DE CHILE. Complementa Resolución 1.910, de 1982, sobre Normas para Viveros, Criaderos y Depósitos de Plantas. Resolución 760 exenta, 1989. Disponible en: www.leychile.cl/Navegar?idNorma=245623\&tipoVersion=0. Acceso: 04.09.2019.

59 THIS IS CHILE. PORTAL OFICIAL DE CHILE, 2010, op. cit.
} 
- Su uso en etiquetas de productos destinados a mercado se hace indispensable con el inicio de las exportaciones en 1987 (GONZÁLEZ FERNÁNDEZ 20070); de estas ventas al exterior probablemente se produce un remanente de productos que se pone a la venta, con las mismas etiquetas, en el mercado interno.

- Con posterioridad, probablemente como estategia comercial, se emplea en el etiquetado de productos pensados para consumidores locales de mayor poder adquisitivo (por ejemplo, en el año 2012, se ofrecía “cheesecake de berries" en una de las cadenas de cafeterías más caras en la principal autopista nacional (de pago), cuyos precios son poco asequibles para el chileno medio).

- Comienza gradualmente a aparecer en rótulos de productos que la mercadotecnia ha denominado superalimentos y de otros elaboraciones con un (supuesto) potencial nutritivo que promete una vida más saludable, muchas veces con ingredientes cuyos nombres rimbombantes tienen la finalidad de prestigiar los productos que los incluyen; son ámbitos que se caracterizan por una alta frecuencia de uso de anglicismos (lo que resulta muy bien ilustrado en la etiqueta del producto NutraPharm Super Berries: "NutraPharm / SuperBerries / Antioxidantes ancestrales / Maqui Blueberry Elderberry Rose hip [sic] / Libre de gluten y sin lactosa / Sin colorantes artificiales / No pesticides / BERRIES ORGÁNICOS / Mezcla potenciada", comprado en Chile en 2015). ${ }^{61}$

- Aparece en alimentos envasados destinados a un público más general, como jugos, yogures, barras de cereales, galletas, e incluso en jabones y productos de limpieza (como en el "Té Negro sabor berries" de la compañía Lipton, la "Locura Berries", un yogur de la empresa Surlat o el "Jabón líquido Ballerina yoghurt/berries/vainilla $1 \mathrm{~L}$ " del Laboratorio Ballerina).

- Se observa su uso en etiquetas y carteles de productos caseros para personas de alto poder adquisitivo, a la venta en pequeños comercios en lugares turísticos (como el "pisco sour de berries" en una carta de cocteles de una cafetería-bar ubicada en un balneario lacustre de la Región de Los Lagos en 2017, o el "Mojito Berrys" en un bar del mismo lugar en el mismo año), como respuesta a la demanda, según los dueños de los lugares en cuestión.

- Se advierte el empleo generalizado de la voz berry/berries, también en compuestos con frutas autóctonas ("Calafate Berry 100\% Polvo de Calafate" en

\footnotetext{
${ }^{60}$ GONZÁLEZ FERNÁNDEZ, 2007, op. cit.

${ }^{61}$ Cf. GARCÍA, Richard. El criollo maqui está de moda como antioxidante y suplemento vitamínico. Asociación Nacional de Investigadores de Postgrado. 5.9.2010. Disponible en: https://anip.cl/el-criollo-maqui-esta-de-modacomo-antioxidante-y-suplemento-vitaminico/. Acceso: 04.09.2019, quien reporta que científicos de la Universidad Austral de Chile desarrollaron un extracto cien veces más potente que la versión natural, presentado como superberry.
} 
la etiqueta de un producto elaborado por la empresa Nativ for Life; o unas cápsulas de "Maqui Berry", que oferece a través de su página web la empresa chilena NATPLUS desde Santiago y en distribución a lo largo del país.

El aspecto más llamativo y el que queremos destacar aquí es el papel de la producción para la venta en el exterior, por un lado, y, por el otro, el de la subsiguiente comercialización de la sobreproducción en el mercado nacional.

El uso que tuvo este anglicismo al comienzo, según reproduce Dyck (2018, 28), de una entrevista con dos miembros de la Fundación Chile, se atribuye a las primeras plantas de blueberries 'arándanos [americanos]' que se importaron a principios de la década de 1980 con la finalidad de iniciar su cultivo comercial en el sur de Chile. Los representantes de la Fundación Chile explican que esa institución fue pionera en la importación de estas especies al país. En cuanto al nombre del fruto, manifiestan que la empresa optó por la "abreviación" berries, porque para la población local la fruta en cuestión era totalmente desconocida hasta este momento. Y su uso como denominación para la exportación obedece a que el objetivo inicial era el posicionamiento de este producto en el mercado estadounidense, donde tradicionalmente se vendían bien otras especias de fruta producida en Chile

Al emplear abreviación, los informantes claramente hacen referencia a un uso del término berry/berries que en la lingüística se consideraría como hiperonímico, es decir, se emplea como hiperónimo de los diferentes frutos para los chilenos mayoritariamente desconocidos en este momento.

Fue la comercialización al extranjero, a países anglohablantes, el motor que impulsó la introducción del vocablo. Estrictamente, en un primer momento no puede considerarse un anglicismo, ya que constituye, en los primeros empleos, una palabra inglesa empleada en un contexto comunicativo en el que el mensaje que se general está destinado a compradores ante todo estadounidenses. Se convierte en anglicismo en el momento de aparecer en la comunicación, en español, entre chilenos.

De la comunicación experta y semiexperta, ingresa en textos dirigidos al público chileno no especializado al venderse en Chile productos etiquetados para la exportación: la aparición en las etiquetas de productos destinados a la exportación incide sobre el desarrollo del anglicismo en el español chileno a través de la comercialización de descartes de exportación o sobreproducción en el mercado nacional, lo que desencadena la presencia de la voz en español fuera de contextos claramente especializados o semiespecializados.

Aquí entra en juego el fenómeno de que, en muchos países, los consumidores creen (a veces con razón) que los productos importados o los productos destinados a la exportación son de mayor calidad. 
El atributo "de exportación", que ya se puede lograr con etiquetas en lengua extranjera que hace visible que se trata de un producto "destinado al consumo en el exterior", puede ser visto como indicador de óptima calidad, y es precisamente este hecho el que hace que también productos de lujo (o al menos de precio alto) muchas veces se comercializan con nombres y etiquetados que confieren un aire de "exportación”, por mucho que no lo sean.

Así, la aparición en productos de exportación provoca la adopción del término en el rotulado de productos de lujo y superalimentos concebidos para el mercado nacional.

Este paso a su vez impacta sobre productos destinados a compradores de menor poder adquisitivo- productos envasados destinados al público general, al que se venden productos con este "rótulo" por su condición de "aumentador de valor representado, o de marca".

Particularmente, parece que ha sido el empleo frecuente de berry/berries en las descripciones de productos, principalmente alimenticios, como yogures, jugos, postres, chocolates, galletas e incluso vinos, el que ha facilitado la incorporación de esta palabra en el léxico habitual de los hablantes para nombrar determinados referentes del tipo baya en Chile.

Esta presencia luego da lugar al empleo también en rótulos hechos a mano, hasta convertirse en normal en el empleo en ámbitos no especializados, en contextos no marcados diafásica y distráticamente, en todo el país.

Con esto, el español de Chile está tomando un camino propio si se compara con lo que se constata en otras variedades del español. Si bien no ha estado en el centro de nuestros análisis, todo indica que berry/berries no ha entrado en otras variedades del español para ocupar un lugar tan prominente. En algunas variedades (argentina, mexicana y peruana) aparece muy, pero muy ocasionalmente, y generalmente en referencia a productos de origen exógeno. La inclusión de esta voz en el español de otros países parece no seguir la ruta trazada por nosotros para Chile. En Argentina, por dar un ejemplo, el uso aparentemente arranca con la comercialización de productos (supuestamente) importados y de alta calidad: helados con recetas supuestamente estadounidenses, nombres rimbombantes y compuestos extranjerizantes. El hecho de que se conste un uso bastante diferente de los equivalentes de berry/berries en las otras variedades diatópicas es otro indicio de un desarrollo bien distinto. Creemos que lo ilustra bien que en internet en español sea frecuente el femenino fruta (del bosque, silvestre, roja, etc.), mientras que solo en el caso del plural se dé la misma relación que constatamos en los textos y contextos chilenos, con más casos del masculino que del femenino, como Helado Premium Sin Lactosa Sabor Frutos Del Bosque de la marca chilena Tavelli, jugos de frutos silvestres: calafate - grosella (OBSERVATORIO PARA LA INNOVACIÓN AGRARIA, 
AGROALIMENTARIA Y FORESTAL para la Innovación Agraria, Agroalimentaria y Forestal ${ }^{62}$ ) o Barra de Cereal Frutos Rojos Yogurt (de la marca chilena Costa).

En el caso de berry/berries en Chile además estamos delante de una ruta curiosa de "implantación" de un anglicismo, ya que el papel de la exportación, que precede a cualquier otro uso de los productos relacionados con el término en cuestión, desempeña un papel tan relevante aquí. Si comparamos este trayecto integrativo con otros casos de anglicismos y con la descripción al respecto en los manuales de terminología, lexicografía o morfología al uso que se ocupan de neología o, muchas veces en el marco de la formación de palabras, de los extranjerismos en general y los anglicismos en particular (cf. ALVAR EZQUERRA, 1983 ${ }^{63}$; LUTZEIER, 1995 ${ }^{64}$; PÖLL, 2002 ${ }^{65}$; DIÉGUEZ, $2004^{66}$, 2005 ${ }^{67}$; ARNTZ; PICHT; MAYER, $2009^{68}$; GERDING; FUENTES, GÓMEZ \& KOTZ, $2016^{69}$; GERDING SALAS; CAÑETE-GONZÁLEZ; ADAM; BLANCO CORREA, 201970, por ejemplo), vemos que la ruta "usual" y mejor descrita es otra, y generalmente va del país productor al país consumidor, y así, de la lengua del país productor a la lengua del país receptor, por así decirlo. De todas formas, llama la atención que en las clasificaciones existentes los criterios aplicados apuntan ante todo al papel o al estatus que estos anglicismos tienen en la lengua receptora (si son aceptados o no por la norma, si son "necesarios", "funcionales", “de lujo", "superfluos”, etc.), a los niveles lingüísticos afectados y los mecanismos formativos (ante todo, si la forma o el significado viene de otra lengua, si es “calco" o "traducción”, etc.), al grado de adaptación (tipográfica, fonética, gramatical), etc., mientras que, dejando el lado la cuestión de si pasan por otras lenguas o si se toman directamente de otra lengua, la ruta por la cual ingresan es un aspecto menos considerado (cf. RODRÍGUEZ MEDINA,

\footnotetext{
${ }^{62}$ OBSERVATORIO PARA LA INNOVACIÓN AGRARIA, AGROALIMENTARIA Y FORESTAL. Formulación e implementación de un plan de marketing para posicionar, captar y comercializar jugos de frutos silvestres (RFNM) de la región de Aysén, Patagonia Chilena, 2019. Disponible en: www.opia.cl/601/w3-article-75311.html (Acceso: 10.9.2019).

${ }^{63}$ ALVAR EZQUERRA, Manuel. Lexicología y lexicografía. Salamanca: Almar, 1983.

${ }^{64}$ LUTZEIER, Peter Rolf. Lexikologie. Tübingen: Stauffenburg, 1995.

${ }^{65}$ PÖLL, Bernhard. Spanische Lexikologie. Eine Einführung. Tübingen: Narr, 2002.

${ }^{66}$ DIÉGUEZ M., M. Isabel. El anglicismo léxico en el discurso económico de divulgación científica del español de Chile. Onomázein 10 (2), 117-141, 2004.

${ }^{67}$ DIÉGUEZ M., M. Isabel. Análisis contrastivo del anglicismo léxico en el discurso económico semiespecializado y de divulgación científica del español de Chile. Onomázein 12, 129-156, 2005.

${ }^{68}$ ARNTZ, Reiner; PICHT, Heribert; MAYER, Felix. Einführung in die Terminologiearbeit. 6., verbesserte Auflage. Hildesheim; Zürich; New York: Olms, 2009.

${ }^{69}$ GERDING, Constanza; FUENTES, Mary; GÓMEZ, Lilian; KOTZ, Gabriela. Anglicisms: An active wordformation mechanism in Spanish. Colombian Applied Linguistics Journal 16 (1), 40-54, 2014.

${ }^{70}$ GERding SAlAS, Constanza; CAÑETE-GONZÁleZ, Paula; ADAM, Carolin; BLANCO CORREA, Blanco Correa, Óscar. Los periodistas y su responsabilidad en la incorporación de préstamos en español. Boletín de Filología 54 (1), 231-254, 2019.
} 
$2000^{71}$, para una revisión crítica de las posiciones en publicaciones respecto de anglicismos en el español).

Por esta razón, el caso reviste especial interés para la investigación y en las explicaciones de los procesos de adopción de extranjerismos en general y de anglicismos en particular, por la interacción de la producción y la comercialización en el extranjero y la venta de descartes de exportación y sobreproducción en el mercado nacional que desempeña un papel tan relevante aquí. Visto desde la tradición de la descripción y clasificación de procesos neológicos relacionados con el empleo de material lingüístico procedente de (o al menos atribuido a) otros idiomas, estamos delante de una posición ciertamente híbrida entre las categorías neológicas establecidas y los motivos de uso y los caminos de integración trazados para otros casos de influencia por otras lenguas.

Es un aspecto reconocido que la importación de conceptos, objetos, tecnologías y demás fenómenos de otra cultura puede conllevar la importación de los términos que los denominan en la cultura de partida, en el sentido de los llamados realia de los estudios de traducción (cf. VLACHOV; FLORIN, 198072). La innovación científica en los ámbitos más diversos se ha identificado como uno de los motores más importantes de la innovación lexical y la adopción de extranjerismos; por ello, un aspecto importante es la permeabilización de la terminología de los lenguajes de especialidad (que muchas veces son los primeros ámbitos de uso de un nuevo elemento léxico) a la lengua común, lo que también conlleva, muchas veces, que los extranjerismos relacionados con objetos (o tecnologías) y el uso de los mismos se impongan en la lengua de los expertos antes de la comercialización y distribución de los objetos en cuestión en la sociedad en general (cf. SINNER, 2013, 270-27773). La ruta que vimos en el caso de berry/berries es muy particular: berry/berries no se usa en Chile como resultado de la llegada de un concepto u objeto que haya llevado a la adopción de un denominador que podría incluirse en el grupo de los realia, ni como consecuencia de la importación de productos que impongan su nombre en el español de Chile. Lo que llegó a Chile fueron especies nuevas de diferentes frutos (inicialmente, ciertos tipos de arándanos), plantas para producir un producto para la exportación, pero la ruta de inserción y divulgación de berry/berries no parte del nombre de dichas plantas o de sus frutos.

\footnotetext{
${ }^{71}$ RODRÍGUEZ MEDINA, María Jesús. El anglicismo en español: revisión crítica del estado de la cuestión. Philologia Hispalensis 14, 99-112, 2000.

${ }^{72}$ VLACHOV, Sergei I.; FLORIN, Sider P. = Влахов, С.И.; Флорин, С.П. Непереводимое в переводе. Москва: Международные Отношения, 1980.

${ }^{73}$ SINNER, Carsten. Indem ich übersetze, übernehme ich Verantwortung. Über die Verantwortung des Übersetzers für seine Sprache. In: ENDE, Anne-Kathrin; HEROLD, Susann; WEILANDT, Annette (Eds.). Alles hängt mit allem zusammen. Translatologische Interdependenzen. Festschrift für Peter A. Schmitt. Berlin: Frank \& Timme, 2013, 251-282.
} 
Tampoco responde, en sus inicios, a los intentos de crear una denominación particularmente "fresca", innovadora, moderna y llamativa, algo que se ha visto como motivo importante de la implantación de anglicismos en la lengua de la publicidad, por ejemplo (cf. JANICH, 2010 ${ }^{74}$, FERRAZ MARTÍNEZ, 2011 ${ }^{75}$ ). La voz berry/berries no tenía que ver, en sus inicios en la lengua española, con un deseo de vender algo con un nombre exótico o diferenciador, pues es, simplemente, el denominador común para un conjunto de frutos con determinados rasgos en común (cf. supra).

También desde la perspectiva de la teoría de los strata lingüísticos se trata de un caso más bien curioso y difícil de categorizar. ${ }^{76} \mathrm{La}$ conocida diferenciación entre elementos de adstrato o adstrato cultural llega a sus límites en este caso, puesto que la adopción del genérico no cumple con los criterios fundamentales para la clasificación como tales. Podría categorizarse como resultado de adstrato cultural en sentido estricto solo si considerásemos como tal el uso del inglés por parte de hispanohablantes para la comunicación con hablantes de inglés en el marco de la comercialización de un producto en el mercado de lengua inglesa, fuera del territorio chileno, pues como vimos, estamos delante del empleo de un elemento en lengua inglesa que inicialmente se hizo pensando en conseguir la entrada en el mercado en lengua inglesa (concretamente, el mercado norteamericano, ante todo, estadounidense). Huelga decir que esta interpretación empujaría al máximo los límites de la categoría adstrato, lo que lo dejaría inoperable (cf. SINNER, 201177, acerca de la interpretación demasiado laxa de la terminología de la teoría de los strata lingüísticos). Tampoco se puede solucionar este reto terminológico mediante una extensión del concepto del adstrato cultural por los llamados contactos virtuales, tal y como se ha propuesto para los contactos lingüísticos como resultado de la comunicación intercultural e interlingüística mediada a través de los nuevos medios. ${ }^{78}$

\footnotetext{
${ }^{74}$ JANICH, Nina. Werbesprache. Ein Arbeitsbuch. Mit einem Beitrag von Jens Runkehl. 5., vollständig überarbeitete und erweiterte Auflage. Tübingen: Narr, 2010.

${ }^{75}$ FERRAZ MARTíNEZ, Antonio. El lenguaje de la publicidad. 9a edición. Madrid: Arco Libros, 2011.

${ }^{76}$ Acerca de los términos substratum, superstratum y adstratum, cf. ASCOLI, [Graziadio Isaia]. 1864. Lingue e nazioni. Il Politecnico 21, 77-100, 1864; GASTON, Paris. Reseña de ASCOLI, G[raziadio] I[saia]. Lettere glottologiche. Prima lettera. Rivista di filologia e d'istruzione classica 10, 1-71, 1882, Romania 11, 130-134, 1882; GRÖBER, Gustav. Vulgärlateinische Substrate romanischer Wörter. Archiv für lateinische Lexikographie und Grammatik 1, 204254, 539-557, 1884; WARTBURG, Walther von. Die Entstehung der Sprachgrenzen im Innern der Romania. Beiträge zur Geschichte der deutschen Sprache und Literatur 58, 209-227, 1934; WARTBURG, Walther von. Die Ausgliederung der Romanischen Sprachräume. Zeitschrift für Romanische Philologie 56, 1-48, 1936; VALKHOFF, Marius. Latijn, Romaans, Roemeens. Openbare les gegeven bij de opening van zijn colleges als privaat-docent in de roemeense taal en letterkunde aan de Universiteit van Amsterdam op 1 November 1932. Amersfoort: Valkhoff \& Co, 1932; VALKHOFF, Marius. Antwort auf einen Fragebogen des Internationalen Linguistenkongresses (Brüssel 1939). In: KONTZI, Reinhold (Ed.). Substrate und Superstrate in den romanischen Sprachen. Darmstadt: Wissenschaftliche Buchgesellschaft, 80, 1982.

77 SINNER, Carsten. Missverständliche und widersprüchliche Darstellung von Substrat, Superstrat, Adstrat in deutschsprachigen Einführungen in die romanische Sprachwissenschaft. Zeitschrift für Romanische Sprachen und ihre Didaktik 5, 1, 69-118, 2011.

${ }^{78}$ En rigor, los contactos virtuales (cf. LANGENBACHER-LIEBEGOTT, Jutta. Sprachkontakte. In: BORN; Joachim et al. (Eds.). Handbuch Spanisch. Sprache, Literatur, Kultur, Geschichte in Spanien und Hispanoamerika. Für
} 
Podría incluirse en una categoría propia, de un caso particular de contactos lingüísticos, consistentes en el uso de una lengua A (en este caso, el inglés) por parte de los hablantes de una lengua B (en este caso, el castellano), y solo si se amalgama este primer paso con el segundo paso del proceso de integración de berry/berries en el español de Chile que vimos, la consiguiente extensión de uso en la comercialización en dicha lengua B, podría llegarse a admitir la posibilidad de ver en este tipo de uso lingüístico una subcategoría de un contacto lingüístico que entraría en la categoría del adstrato cultural, o, más bien, adstrato por comercialización: dado que el meollo de la cuestión radica en el acto de adaptación del vendedor al mercado, a su comprador, que en este caso es, en primera instancia, estadounidense, y se podría argumentar que se trataría, por así decirlo, de un adstrato por comercialización.

Este curioso caso de un anglicismo resultante de la globalización de los mercados, en forma de producción y venta de fruta de un continente a otro, se diferencia de otros efectos lingüísticos de la globalización por la dirección inicial de la comercialización (que es una forma más de comunicación). La ruta no sigue el trayecto de una cultura dominante, "colonizadora", a otra "colonizada", dominada cultural y económicamente, sino que se trata de un caso en el que la globalización lleva a la exportación desde un país "dominado" a uno dominante, siendo que la integración del anglicismo pasa precisamente por el paso previo de la exportación de productos (chilenos) extraídos anteriormente del mismo país dominante, con un efecto lingüístico, empero, sobre la cultura dominada que exporta el producto. Como de alguna forma se invierte o, mejor dicho, distorsiona el patrón general de transmisión, sin duda es pertinente y fecundador ligar esta perspectiva con la de los estudios postcoloniales.

\section{Consideraciones finales}

Presentamos y debatimos, en este trabajo, un anglicismo que constituye un caso particular por diferentes razones. En el estudio que dio lugar a esta contribución, se pudo trazar un camino evolutivo del anglicismo berry/berries en el español de Chile que, a partir del mero uso en nombres de empresas del sector, y pasando por la aparición en textos especializados y semiespecializados y la prensa no especializada, llega a utilizarse en etiquetas de productos de exportación y, más tarde, se incluye en el rotulado de productos de lujo y superalimentos, para luego aparecer en productos envasados destinados al público general y finalmente darse también en rótulos hechos a mano, convirtiéndose, a 
lo largo de este trayecto, en un elemento normal de uso en las diferentes variedades diasistemáticas en todo el país.

El caso de berry/berries es muy diferente de lo que normalmente se encuentra al analizar los anglicismos del castellano, por los motivos iniciales del empleo, por el camino tomado, por la posición tan particular en comparación con lo que se constata en otras variedades hispanas y, finalmente, por establecer, en el castellano de Chile, un nuevo hiperónimo para una nueva conceptualización, ya que el grupo de elementos que abarca, que no existía en la cultura chilena (ni en la hispanohablante en su conjunto), hoy forma parte del léxico habitual.

Finalmente, la nueva mirada al concepto de adstrato cultural, incorporando el aspecto de la comercialización destinada a la comunidad hablante de la lengua que provee el préstamo como punto de arranque para la incorporación de una unidad extranjera que después se masifica en la comunidad receptora, es un enfoque que estimamos de suyo novedoso. 


\section{Referencias bibliográficas}

ALVAR EZQUERRA, Manuel. Lexicología y lexicografía. Salamanca: Almar, 1983.

ARNTZ, Reiner; PICHT, Heribert; MAYER, Felix. Einführung in die Terminologiearbeit. 6., verbesserte Auflage. Hildesheim; Zürich; New York: Olms, 2009.

ASCOLI, [Graziadio Isaia]. 1864. Lingue e nazioni. Il Politecnico 21, 77-100, 1864.

BHP BILLITON. BHP. 2019. Disponible en https://www.bhp.com/espanol. Acceso: 02.08.2019.

BIBLIOTECA DEL CONGRESO NACIONAL DE CHILE. Modifica resolución No. 1.910 de 1982 sobre normas para criaderos, viveros y depósitos y deroga resolución No. 760 de 1989. 2019. Disponible en:

www.leychile.cl/Navegar?idNorma=245622\&idParte=\&idVersion=2011-02-17, versión corta de la URL https://bcn.cl/27nt4. Acceso: 19.07.2019.

CAMBRIDGE UNIVERSITY PRESS. Cambridge Dictionary. Sin fecha. Cambridge: Cambridge University Press. Disponible en: https://dictionary.cambridge.org/es/. Acceso: 07.07.2019.

CASTRO, Lorena. A disfrutar de los berries este verano. Siminforma 491 (diciembre de 2018).

Disponible en: http://www.siminforma.com.mx/Siminforma-Chile/pdf/491.pdf. Acceso: 19.07.2019.

CHRISTIAN, Shirley. After Turmoil, Foundation Finds Profit. In: South Florida SunSentinel, 12.09.1988, www.sun-sentinel.com/news/fl-xpm-1988-09-12-8802220574-story.html. Acceso: 09.08.2019.

DAVIES, Mark. Corpus del español. Disponible en: https://www.corpusdelespanol.org/hist-gen/.

DIÉGUEZ M., M. Isabel. El anglicismo léxico en el discurso económico de divulgación científica del español de Chile. Onomázein 10 (2), 117-141, 2004.

DIÉGUEZ M., M. Isabel. Análisis contrastivo del anglicismo léxico en el discurso económico semiespecializado y de divulgación científica del español de Chile. Onomázein 12, 129-156, 2005.

DYCK, Gabriela. Zur Entwicklung des Terminus berries im chilenischen Spanisch zwischen 1985 und 2012. Tesis de máster. Leipzig: Institut für Angewandte Linguistik und Translatologie, Universität Leipzig, 2018.

FERRAZ MARTÍNEZ, Antonio. El lenguaje de la publicidad. 9a edición. Madrid: Arco Libros, 2011.

FUNDACIÓN CHILE. Berries. 2015. Disponible en: https://fch.cl/berries-2/. Acceso: 12.07.2019.

GAMEZ BASTÉN, María Eugenia. El sector berries en Chile. [Página web de la] Oficina de Estudios y Políticas Agrarias del Gobierno de Chile, 12.03.2002. Disponible en: www.odepa.gob.cl/publicaciones/articulos/el-sector-berries-en-chile-2002. Acceso: 20.10.2020. 
GARCÍA, Richard. El criollo maqui está de moda como antioxidante y suplemento vitamínico. Asociación Nacional de Investigadores de Postgrado. 5.9.2010. Disponible en: https://anip.cl/el-criollo-maqui-esta-de-moda-como-antioxidante-y-suplemento-vitaminico/. Acceso: 04.09.2019

GASTON, Paris. Reseña de ASCOLI, G[raziadio] I[saia]. Lettere glottologiche. Prima lettera. Rivista di filologia e d'istruzione classica 10, 1-71, 1882, Romania 11, 130-134, 1882.

GERDING, Constanza; FUENTES, Mary; GÓMEZ, Lilian; KOTZ, Gabriela. Anglicisms: An active word-formation mechanism in Spanish. Colombian Applied Linguistics Journal 16 (1), 40-54, 2014.

GERDING SALAS, Constanza; CAÑETE GONZÁLEZ, Paola; ADAM, Carolin. Neología sintagmática anglicada en español: Calcos y préstamos. Revista Signos. Estudios de Lingüística 51, 175-192, 2018. DOI: http://dx.doi.org/10.4067/S0718-09342018000200175.

GERDING SALAS, Constanza; CAÑETE-GONZÁLEZ, Paula; ADAM, Carolin; BLANCO CORREA, Blanco Correa, Óscar. Los periodistas y su responsabilidad en la incorporación de préstamos en español. Boletín de Filología 54 (1), 231-254, 2019.

GERDING SALAS, Constanza; FUENTES MORRISON, Mary; KOTZ GRABOLE, Gabriela. Anglicismos y aculturación en la sociedad chilena. Onomázein 25, 139-162, 2012.

GERDING SALAS, Constanza, et al. Los periodistas y su responsabilidad en la incorporación de préstamos en español. Boletín de Filología 54, 1, 231-254, 2019. DOI: http://dx.doi.org/10.4067/S0718-93032019000100231.

GÓMEZ CAPUZ, Juan. El tratamiento del préstamo lingüístico y el calco en los libros de texto de bachillerato y en las obras divulgativas. Tonos digital: Revista electrónica de estudios filológicos 17, 2009. Disponible en: www.um.es/tonosdigital/znum17/secciones/tritonos-1librosdetexto.htm. Acceso: 20.10.2020.

GONZÁLEZ FERNÁNDEZ, Rodrigo. Los Grob en La Unión. AGRICULTURA BLOGGER. Defendamos nuestra Agricultura una forma de vida. 2007. Disponible en: http://agriculturablogger.blogspot.com/2007/10/los-grob-en-la-union-e-la-revistadel.\%20html. Acceso: 14.07.2019.

GRIMM, Rüdiger. Digitale Kommunikation. München: Oldenbourg, 2005).

GRÖBER, Gustav. Vulgärlateinische Substrate romanischer Wörter. Archiv für lateinische Lexikographie und Grammatik 1, 204-254, 539-557, 1884.

INDURÁIN PONS, Jordi (Ed.). Diccionario general de la lengua española. El vocabulario general del español de América y Europa. Tercera edición. Barcelona: VOX, 2011.

INNOVACION.CL. El maqui, la murta y el calafate son propios de nuestro país. Berries nativos: Una nueva oportunidad para la exportación de Chile. Innovacion.cl. 25.02.2015. Disponible 
en: www.innovacion.c1/2015/02/berries-nativos-una-nueva-oportunidad-para-la-exportacionde-chile/. Acceso: 20.10.2020.

INSTITUTO DE CHILE. Diccionario de uso del español de Chile. 2019. Disponible en www.institutodechile.cl/lengua2/diccionario-de-uso-del-espanol-de-chile/. Acceso:19.07.2019.

INSTITUTO DE INVESTIGACIONES AGROPECUARIAS (INIA). Manual de Arándano. 2013. Disponible en http://biblioteca.inia.cl/medios/biblioteca/boletines/NR39094.pdf. Acceso: 24.08.2019.

INTERNATIONAL UNION FOR THE PROTECTION OF NEW VARIETIES OF PLANTS / Internationaler Verband zum Schutz von Pflanzenzüchtungen. Sanddorn. UPOV-Code HIPPH_RHA. Hippophae rhamnoides L. Richtlinien für die Durchführung auf Unterscheidbarkeit, Homogenität und Beständigkeit. Genf: UPOV, 2008.

JANICH, Nina. Werbesprache. Ein Arbeitsbuch. Mit einem Beitrag von Jens Runkehl. 5., vollständig überarbeitete und erweiterte Auflage. Tübingen: Narr, 2010.

LANGENBACHER-LIEBEGOTT, Jutta. Sprachkontakte. In: BORN; Joachim et al. (Eds.). Handbuch Spanisch. Sprache, Literatur, Kultur, Geschichte in Spanien und Hispanoamerika. Für Studium, Lehre, Praxis. Berlin: Schmitt, 2012, 146-156

LEGUE GONZÁLEZ, Ana; SANDOVAL HERNÁNDEZ, Catalina. ¿Helado de berries o de frutos del bosque? Variantes ortotipográficas y frecuencia de uso del anglicismo berry y de sus equivalentes en español. Tesis para optar al grado de Licenciado. Concepción: Universidad de Concepción, 2019

LEXICO. Oxford English and Spanish Dictionary, Thesaurus, and Spanish to English Translator. Sin fecha. Disponible en: www.lexico.com/en/english. Acceso: 07.07.2019.

LORGE, Greta. Bananas are berries? Stanford Magazine July/August 2013. Disponible en: https://stanfordmag.org/contents/bananas-are-berries. Acceso: 05.07.2019.

LUTZEIER, Peter Rolf. Lexikologie. Tübingen: Stauffenburg, 1995.

MERRIAM-WEBSTER. Merriam-Webster. Sin fecha. Disponible en: https://www.merriamwebster.com. Acceso: 19.10.2020.

MINISTERIO DE AGRICULTURA DE CHILE. Complementa Resolución 1.910, de 1982, sobre Normas para Viveros, Criaderos y Depósitos de Plantas. Resolución 760 exenta, 1989. Disponible en: www.leychile.cl/Navegar?idNorma $=245623 \&$ tipoVersion=0 . Acceso: 04.09.2019.

MOLINER, María. Diccionario de uso del español. Gredos: Madrid, 2008.

MORALES PETTORINO, Félix. Nuevo diccionario ejemplificado de chilenismos, edición refundida y actualizada. Valparaíso: Puntángeles, 2010. 
NOVOTNÁ, Markéta. El anglicismo en la lengua española. Brno: Masarykova univerzita, 2007. Disponible en: https://is.muni.cz/th/145734/ff_b/bakalarska_diplomova_prace.pdf. Acceso: 02.10.2020.

\section{OBSERVATORIO PARA LA INNOVACIÓN AGRARIA, AGROALIMENTARIA Y}

FORESTAL. Formulación e implementación de un plan de marketing para posicionar, captar y comercializar jugos de frutos silvestres (RFNM) de la región de Aysén, Patagonia Chilena, 2019. Disponible en: www.opia.cl/601/w3-article-75311.html (Acceso: 10.9.2019).

OKSAAR, Els. Idiolekt. In: AMMON, Ulrich; DITTMAR, Norbert; MATTHEIER, Klaus J. (Eds.). Sociolinguistics. Soziolinguistik. An International Handbook of the Science of Language and Society. Ein Internationales Handbuch zur Wissenschaft von Sprache und Gesellschaft. 2 vols. Berlin: de Gruyter, Vol 1, 293-297, 1987.

OKSAAR, Els. Idiolekt als Grundlage der variationsorientierten Linguistik. Sociolinguistica 14, 37-42, 2000.

PÖLL, Bernhard. Spanische Lexikologie. Eine Einführung. Tübingen: Narr, 2002.

REAL ACADEMIA ESPAÑOLA. Corpus Diacrónico del Español (CORDE). Disponible en: http://corpus.rae.es/cordenet.html.

REAL ACADEMIA ESPAÑOLA. Corpus de Referencia del Español Actual (CREA).

Disponible en: http://corpus.rae.es/creanet.html.

REAL ACADEMIA ESPAÑOLA / ASOCIACIÓN DE ACADEMIAS DE LA LENGUA ESPAÑOLA. Diccionario de la lengua española. Versión electrónica 23.3, actualización 2019. 2019. Disponible en: https://www.rae.es. Acceso: 19.10.2020.

REDAGRÍCOLA. Arándanos. Entrevista al asesor internacional Sebastián Ochoa. Variedades de arándano para una industria ya madura. Redagrícola. Junio 2019. Disponible en www.redagricola.com/cl/variedades-dearandano-para-una-industria-ya-madura/\#: :text=En\%20la\%20zona\%20norte\%20de\%20Chile \%20queremos\%20variedades\%20que\%20se,de\%20gran\%20desarrollo\%20en\%20Perú. Acceso: 25.10.2020.

REGIÓN DE LOS RÍOS, GOBIERNO REGIONAL. Los Ríos. Región de oportunidades. Propuestas de Inversión, Corporación Regional de Desarrollo Productivo. 2016. Disponible en: https://corporacionlosrios.cl/index.php/files/419/Propuestas\%20de\%20Inversion/754/Descargar \%20aqui.pdf. Acceso: 27.08.2019.

RODRÍGUEZ MEDINA, María Jesús. El anglicismo en español: revisión crítica del estado de la cuestión. Philologia Hispalensis 14, 99-112, 2000.

SANTAMARÍA, Isabel. La representación de la resemantización en los diccionarios del español. Revista de Lexicografía 19, 139-166, 2013. 
SINNER, Carsten. Missverständliche und widersprüchliche Darstellung von Substrat, Superstrat, Adstrat in deutschsprachigen Einführungen in die romanische Sprachwissenschaft. Zeitschrift für Romanische Sprachen und ihre Didaktik 5, 1, 69-118, 2011.

SINNER, Carsten. Wissenschaftliches Schreiben in Portugal zum Ende des Antigo Regime (1779-1821). Die Memórias económicas der Academia das Ciências de Lisboa. Berlin: Frank\&Timme, 2012.

SINNER, Carsten. Indem ich übersetze, übernehme ich Verantwortung. Über die Verantwortung des Übersetzers für seine Sprache. In: ENDE, Anne-Kathrin; HEROLD, Susann; WEILANDT, Annette (Eds.). Alles hängt mit allem zusammen. Translatologische Interdependenzen. Festschrift für Peter A. Schmitt. Berlin: Frank \& Timme, 2013, 251282.

SINNER, Carsten. Varietätenlinguistik. Eine Einführung. Tübingen: Narr, 2014.

SINNER, Carsten. Mito y realidad del impacto de los nuevos medios de comunicación en la lengua. El caso del castellano. In: CARRISCONDO ESQUIVEL, Francisco M. (Ed.). El español como noticia y el español de los medios. Vigo: Editorial Academia del Hispanismo, 2016, p. 161207.

SINNER, Carsten. Language Change through Medial Communication. In: BEDIJS, Kristina Bedijs / MAASS, Christiane (Ed.). Manual of Romance Languages in the Media. Berlin / Boston: de Gruyter Mouton, 2017, p. 381-410.

SINNER, Carsten; GERDING SALAS, Constanza. La introducción del anglicismo berry/berries en el español de Chile: historia, proceso integrativo y consecuencias semánticas. Zeitschrift für romanische Philologie, v. 136, $\mathrm{n}^{\circ}$ 3, p. 789-832, 2020.

THIS IS CHILE. PORTAL OFICIAL DE CHILE. El boom de los berries chilenos. 22.01.2010, Disponible en https://www.thisischile.cl/el-boom-de-los-berries-chilenos/. Acceso: 04.09.2019.

VALKHOFF, Marius. Latijn, Romaans, Roemeens. Openbare les gegeven bij de opening van zijn colleges als privaat-docent in de roemeense taal en letterkunde aan de Universiteit van Amsterdam op 1 November 1932. Amersfoort: Valkhoff \& Co, 1932.

VALKHOFF, Marius. Antwort auf einen Fragebogen des Internationalen Linguistenkongresses (Brüssel 1939). In: KONTZI, Reinhold (Ed.). Substrate und Superstrate in den romanischen Sprachen. Darmstadt: Wissenschaftliche Buchgesellschaft, 80, 1982.

VLACHOV, Sergei I.; FLORIN, Sider P. = Влахов, С.И.; Флорин, С.П. Непереводимое в переводе. Москва: Международные Отношения, 1980.

WARTBURG, Walther von. Die Entstehung der Sprachgrenzen im Innern der Romania. Beiträge zur Geschichte der deutschen Sprache und Literatur 58, 209-227, 1934. 
WARTBURG, Walther von. Die Ausgliederung der Romanischen Sprachräume. Zeitschrift für Romanische Philologie 56, 1-48, 1936.

WOLL, Dieter. Der ,Mais' wird zur ,Hirse', der ,Jaguar' zum, Tiger': europäisch-portugiesische Wörter für Dinge der Neuen Welt. In: ENDRUSCHAT, Annette / SCHÖNBERGER, Axel (Eds.). Neue Beiträge zur portugiesischen Sprachwissenschaft. Frankfurt am Main: TFM, 11-47, 1999. 